\title{
CHEMOSPHERE
}

\section{Degradation of azo dye Acid Red 14 in aqueous solution by electrokinetic and electrooxidation process}

\author{
Aimin Wang, Jiuhui Qu *, Huijuan Liu, Jiantuan Ge \\ State Key Laboratory of Environmental Aquatic Chemistry, Research Center for Eco-Environmental Sciences, \\ Chinese Academy of Sciences, P.O. Box 2871, Beijing 100085, China
}

Received 11 July 2003; received in revised form 12 December 2003; accepted 23 January 2004

\begin{abstract}
A new wastewater treatment technology-electrokinetic-electrooxidation process (EK-EO process) is developed in this paper. The EK-EO process can take advantage of both electrooxidation on the anode surface and the electrokinetic process of anionic impurities under an electric field, which can enhance the TOC removal in electrolysis process. The degradation of an anionic azo dye Acid Red 14 (AR14) was experimentally investigated. It was found that under an electric field AR14 could be migrated into anode compartment and be efficiently mineralized. After 360 min electrolysis of $100 \mathrm{mgl}^{-1}$ AR14 solutions at $4.5 \mathrm{~mA} \mathrm{~cm}^{-2}$, complete discoloration was observed in both cathode and anode compartment. About $60 \%$ TOC was electromigrated from cathode compartment to anode compartment, and more than $25 \mathrm{mg}^{-1}$ TOC was abated in anode compartment. A possible degradation mechanism of AR 14 by EK-EO process was proposed. Additionally, the effect of current density, recycling flux, and electrolyte concentration on the EK-EO degradation of AR14 was also investigated.
\end{abstract}

(C) 2004 Published by Elsevier Ltd.

Keywords: Electrokinetic-electrooxidation process; Acid Red 14; Degradation; Decoloration

\section{Introduction}

Dye pollutant from the textile industry is a dangerous source of environmental contamination. For the removal of such recalcitrant pollutant, traditional physical techniques (coagulation, adsorption on activated carbon, reverse osmosis and ultrafiltration, etc.) can generally be used (Vandevivere et al., 1998). Nevertheless, these methods are usually non-destructive, and the posttreatment of the adsorbent materials or solid wastes is necessary and expensive (Galindo et al., 2001).

Recently, some electrochemical technologies known as advanced oxidation processes (AOPs) have attracted an increasing scientific and technique attention (Ra-

\footnotetext{
${ }^{*}$ Corresponding author. Tel.: +86-10-628-49151; fax: +8610-629-23558.

E-mail address: jhqu@mail.rcees.ac.cn (J. Qu).
}

jeshwar et al., 1994; Trasatti, 1995; Coin et al., 1996; Simmon, 1997; Jüttner et al., 2000). These technologies are based on the generation of very reactive species such as hydroxyl radicals. Owing to their high oxidation potential $\left(E^{0}=+2.80 \mathrm{~V}\right)$, the $\cdot \mathrm{OH}$ radicals were extraordinarily reactive oxidants and can attack the most part of organic molecules with rate constants usually in the order of $10^{6}-10^{9} \mathrm{M}^{-1} \mathrm{~s}^{-1}$ (Andreozzi et al., 1999; Wang and Lemley, 2002).

While electrochemical techniques are more environmentally friendly than the chemical methods in polluted water treatment, a significant drawback is that parasitic reactions, such as electrolysis of water, often compete with electrolysis of the contaminant and lower energy efficiency (Rodger and Bunce, 2001). It is quite necessary to improve the efficiency of electrochemical techniques. Recently, some methods that have been tried to overcome these problems have been reported. The researches have focused on the use of catalytic electrodes with high-applied 
potentials, such as $\mathrm{SnO}_{2} / \mathrm{Ti}$ anode (Comninellis and Pulgarin, 1993; Pulgarin et al., 1994; Panizza et al., 2000) and $\mathrm{PbO}_{2} / \mathrm{Ti}$ anode (Schümann and Gründler, 1998), and on the modification of the structure of electrode, such as the three-dimensional electrode (Xiong et al., 2001). The goals of these methods are to produce hydroxyl radicals efficiently and to make the most of these radicals to mineralize organic pollutants. However, less attention has been paid to utilizing the function of electric field in the electrochemical treatment.

The electrochemical degradation rate depends on the initial condition of organic pollutant. When the organic concentration is high, the average current efficiency is high (Comninellis and Pulgarin, 1991). Since the lifetime of hydroxyl radicals is short (only few nanoseconds), they can only react where they are formed (Galindo et al., 2001). Increasing the quantity of organic pollutant per volume unit theoretically enhances the probability of collision between organic matter and oxidizing species, leading to an increase in the degradation rate. Enhancing the organic concentration may be a practicable way to improve treatment efficiency. This aim may be realized through electrokinetic techniques which have recently received considerable interest in the field of soil remediation (Acar et al., 1992; Acar and Alshawabkeh, 1993; Acar et al., 1995; Dzenitis, 1997). The primary contaminant transport mechanisms that occur during electrokinetics are electromigration, electroosmosis and electrophoresis (Saichek and Reddy, 2003).

In the present paper, we introduced the electrokinetic process into the electrochemical method to wastewater treatment. The electrokinetic process was combined with the electrooxidation technique by laying an ultrafilter membrane between the anode and cathode. The ultrafilter membrane could prevent the solution from free movement between anode compartment and cathode compartment and allow the ionic organic pollutant transport across it under the electric field. In the anode compartment the organic pollutant might be oxidized on the anode through direct or indirect electrooxidation course. The degradation of an anionic dye AR14, commonly named Acid Red B, was examined by this process and the optimum conditions were also detected.

\section{Materials and methods}

\subsection{Materials}

An azo dye AR14 was selected as the model compound, which was commercial dyes and used without further purification. Its chemical structure was given in Fig. 1. Acetonitrile was HPLC grade from Fisher Scientific. All other chemicals were of analytical grade. Deionized and double distilled water was used throughout this study.

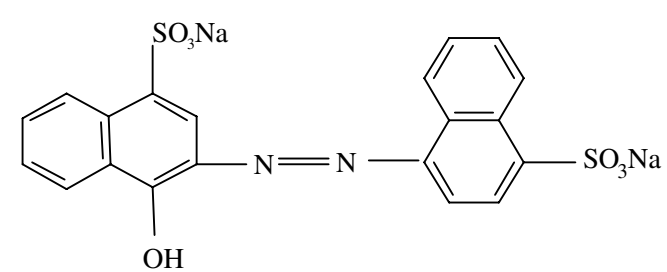

Acid Red 14 (AR14)

C. I. 14720

Fig. 1. Chemical structure of AR14.

\subsection{Apparatus}

All electrochemical experiments were carried batchwise in a two-compartment cell with a total volume of $500 \mathrm{ml}$. The anode and cathode compartments (each of $250 \mathrm{ml}$ ) were separated by an ultrafilter membrane (PES, PPC, Beijing Zhongke Membrane Technology Co. Ltd., Beijing). Such membrane was located at a $10 \mathrm{~mm}$ distance from both electrodes (Fig. 2). The setup had two recirculation systems. Each of them included a reservoir of 11 , which contained the AR14 solution, and a peristaltic pump which continuously recirculated the reactor content. The $\mathrm{SnO}_{2} / \mathrm{Ti}$ anode was kindly provided by Whizzo Science and Technology Co. Ltd. (Shenyang, China), and the cathode was a nickel plate. The surface of each electrode was $81 \mathrm{~cm}^{2}$.

\subsection{Analytical procedures}

Samples were taken from the anode and cathode reservoirs at time $0,30,60,90,120,180,270,360 \mathrm{~min}$, and filtered through a $0.45 \mu \mathrm{m}$ filter. The samples $\mathrm{pH}$ was adjusted to 7.0 with $0.2 \mathrm{M} \mathrm{NaOH}$ or $\mathrm{H}_{2} \mathrm{SO}_{4}$ using Orion 720APLUS Benchtop meter (Thermo Orion Co., USA), and then the UV-Vis spectra of the samples were

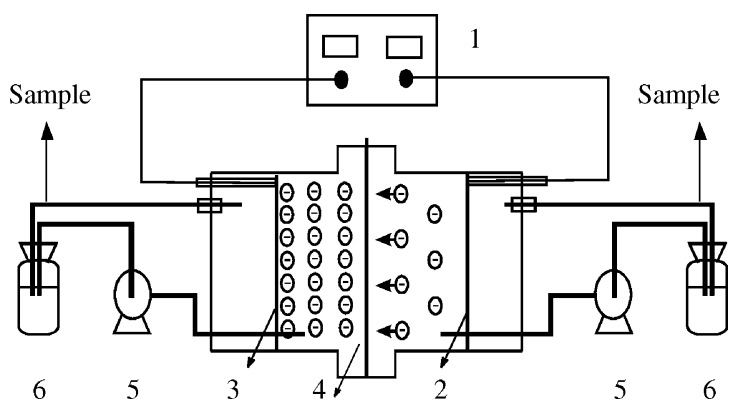

Fig. 2. Schematic of the pilot flow reactor used for AR14 degradation flow experiment: (1) power supply; (2) Ni cathode plate; (3) $\mathrm{SnO}_{2} / \mathrm{Ti}$ anode plate; (4) ultrafilter membrane; (5) pump; (6) reservoir. 
recorded from 190 to $650 \mathrm{~nm}$ using a U-3010 UV-Vis spectrophotometer (Hitachi Co., Japan). The chroma of wastewater was determined by measuring the absorbance at a fixed wavelength $(514 \mathrm{~nm})$, which was corresponded to the maximum absorption wavelength, using a UV-752 spectrophotometer (Shanghai, China).

AR14 and its oxidation products were analyzed on a HP 1050 reverse-phase chromatograph (HPLC, HP, USA). The separation was performed using a Zorbax Extend-C18 reversed phase column ( $5 \mu \mathrm{m}, 250 \mathrm{~mm} \times 4.6$ mm i.d.) (Agilent Technologies, USA). An UV detector was used with the wavelength set at $254 \mathrm{~nm}$. The mobile phase composed of acetonitrile- $0.05 \mathrm{M}$ aqueous ammonium acetate water $(30 / 70(\mathrm{v} / \mathrm{v}))$ at a flowrate of 0.9

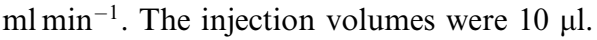

Total organic carbon (TOC) in water was measured by a Phoenix 8000 TOC analyzer (Tekmar-Dohrmann Co., USA).

\section{Results and discussion}

\subsection{The mechanism of AR14 decoloration and degrada- tion in $E K-E O$ process}

In the electrokinetic and electrooxidation (EK-EO) process, the ultrafilter membrane could prevent the solution from mixing and allow the ionic impurities to penetrate through it at the function of electric field. The reaction conditions were as follows: current density 4.5 $\mathrm{mA} \mathrm{cm}{ }^{-2}$, recirculation flow $125 \mathrm{ml} \mathrm{min}^{-1}$ and $\mathrm{Na}_{2} \mathrm{SO}_{4}$ concentration $0.02 \mathrm{M}$.

\subsubsection{Decoloration of AR14 in cathode compartment}

The changes in the UV-Vis spectra of AR14 from 190 to $650 \mathrm{~nm}$ were measured and the selected UV spectra for the electrokinetic process in cathode compartment were depicted in Fig. 3. As shown in Fig. 3, the characteristic absorption band of AR14 decreased dramatically with electrolysis time. The decrease of absorption peaks of AR14 at $\lambda_{\max }=514 \mathrm{~nm}$ in this figure indicated a rapid lessen of azo dye. There were two decisive factors that lead to the decoloration of AR14 in cathode compartment. This could be confirmed by the curves of Fig. 4 in which the results of the removal of color and TOC were presented. It showed clearly that the removal of color was much faster than that of the TOC. Nearly complete discoloration of AR14 were observed after $360 \mathrm{~min}$ electrolysis while only about $60 \%$ TOC was removed. This indicated that while most of AR14 molecules electromigrated into anode compartment (main TOC removal), some of them might be reduced on cathode surface and decolorized according to the following reaction (Bechtold et al., 2002):

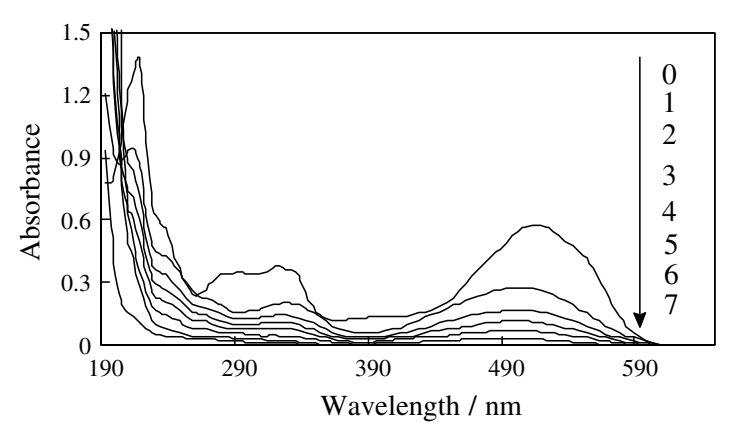

Fig. 3. UV-Vis spectra changes of AR14 solution with a 5-fold dilution in cathode compartment. Spectra from top to bottom $(0-7)$ refer to the electrolysis times $0,30,60,90,120,180,270$, $360 \mathrm{~min}$, respectively.

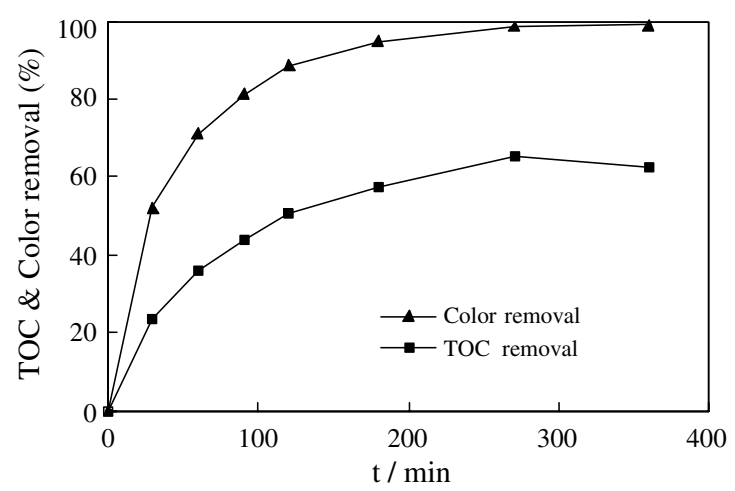

Fig. 4. Abatement of TOC and apparent color in cathode compartment during EK-EO process.

$-\mathrm{N}=\mathrm{N}-+2 \mathrm{e}^{-}+2 \mathrm{H}^{+} \Longleftrightarrow-\mathrm{NH}-\mathrm{HN}_{-}$

$-\mathrm{NH}-\mathrm{HN}-+2 \mathrm{e}^{-}+2 \mathrm{H}^{+} \Longleftrightarrow-\mathrm{NH}_{2}+\mathrm{H}_{2} \mathrm{~N}-$

So it could be concluded that both the electromigration and electroreduction in cathode compartment contributed to the decoloration of AR14 in aqueous solution.

\subsubsection{Degradation of AR14 in anode compartment}

To study the degradation process of AR14 in anode compartment, the products formed during electrolysis were analyzed by UV-Vis spectra and HPLC spectroscopy. Firstly, UV-Vis spectra of samples taken before and after EK-EO process in anode compartment were compared. Representative UV-Vis spectra of the dye solution as a function of time for EK-EO treatment were shown in Fig. 5. The UV-Vis spectrum of AR14 mainly consisted of three well-resolved bands. They were 514, 322 and $220 \mathrm{~nm}$, respectively. The lowest energy absorption band $(514 \mathrm{~nm})$ was assigned to the $\mathrm{n}-\pi^{*}$ transition of $-\mathrm{N}=\mathrm{N}-$ group (Solozhenko et al., 1995). 


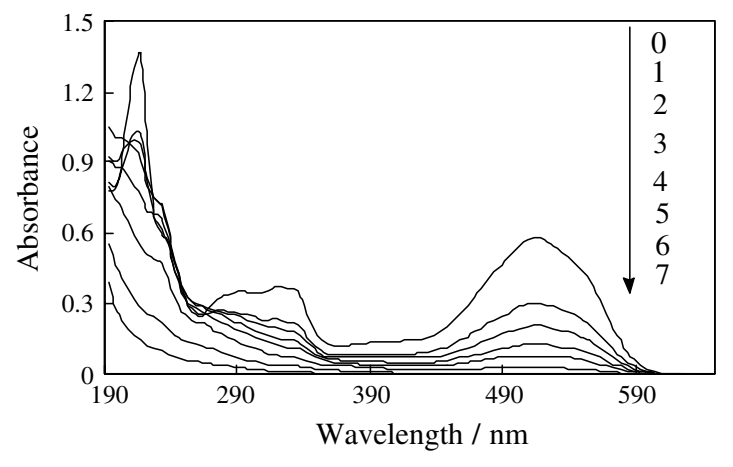

Fig. 5. UV-Vis spectra changes of AR14 solution with a 5-fold dilution in anode compartment. Spectra from top to bottom refer to the electrolysis times $0,30,60,90,120,180,270,360$ min, respectively.

The peaks at 220 and $322 \mathrm{~nm}$ were the absorption of the $\pi-\pi^{*}$ transition related to the naphthalene rings bonded to the $-\mathrm{N}=\mathrm{N}-$ group in the dye molecule (Wu et al., 2000; Xiong et al., 2001). It was apparent that the AR14 decreased dramatically with increasing reaction time and did not show any new absorbance bands in the UV-Vis region (Fig. 5). In Fig. 6, the changes in TOC value and color removal in the anode compartment were depicted. As could be seen, the results revealed that TOC increased up to its peak value of $39 \mathrm{mg}^{-1}$ during the first $180 \mathrm{~min}$. Thereafter, the TOC dropped gradually to 25 $\mathrm{mgl}^{-1}$ after $360 \mathrm{~min}$. This trend could be related to the fact that both electrooxidation and electromigration took place simultaneously, more organics was migrated from cathode compartment than that mineralized on the anode during the period of $180 \mathrm{~min}$, the TOC was increasing; and after 180 min more organics was mineralized than that migrated from the cathode compartment, the TOC was decreasing. After $360 \mathrm{~min}$ treatment the solution in anode compartment fully decolorized as well as $25 \mathrm{mg}^{-1}$ TOC remained. This indicated that the disappearance of AR14 was rapid, but the mineralization of organic intermediates was relatively slow.

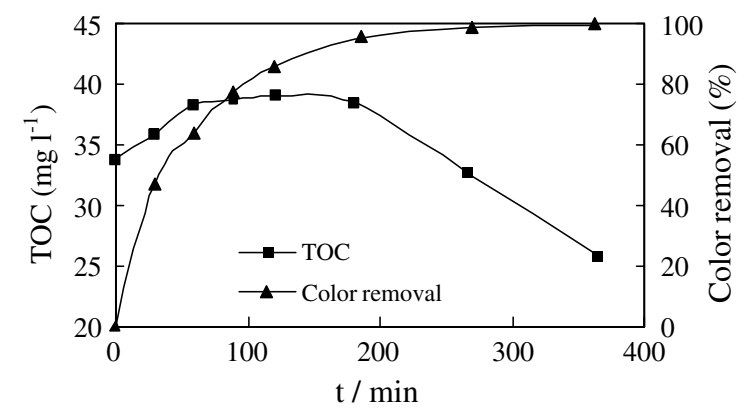

Fig. 6. Elimination of TOC and apparent color in anode compartment during EK-EO process.
Since AR14 was mineralized mainly in anode compartment, its change in anode compartment was followed by HPLC analysis. Since the fact that the charged intermediates of AR14 might electromigrate into the cathode or anode compartment, we did not identify the intermediates by LC/MS or other analytical techniques. Fig. 7 showed the chromatograms of the solution samples which were taken from the anode compartment during the electrochemical degradation of the AR14.

The initial solution (curve 1) showed only a large peak due to AR14, with the retention time $t_{\mathrm{R}}=3.03$ min. The sample taken after $60 \mathrm{~min}$ (curve 2) exhibited a diminished AR14 peak and a couple of new peaks due to the degradation intermediates in the range of retention times $\left(t_{\mathrm{R}}\right)$ from 2.27 to $5.76 \mathrm{~min}$. After 120 and $360 \mathrm{~min}$ electrolysis the chromatograms (curve 3 and 4) displayed a decreasing peak intensity of AR14 and many increasing degraded intermediates' peaks $\left(t_{\mathrm{R}}: 2.26,3.46\right.$ min etc.). This was the result that AR14 was continuously electromigrated from cathode compartment, then quickly oxidized and formed intermediates in anode compartment. Despite these products might continue to be oxidized by hydroxyl radicals, the formation was much more than the elimination of them in a period of $360 \mathrm{~min}$. As shown in curve 4 of Fig. 7, after $360 \mathrm{~min}$ EK-EO treatment, a few organic intermediates in solution were still remained in the anode compartment.

From the above, we could conclude that the EKEO process consisted of the electrooxidation on anode

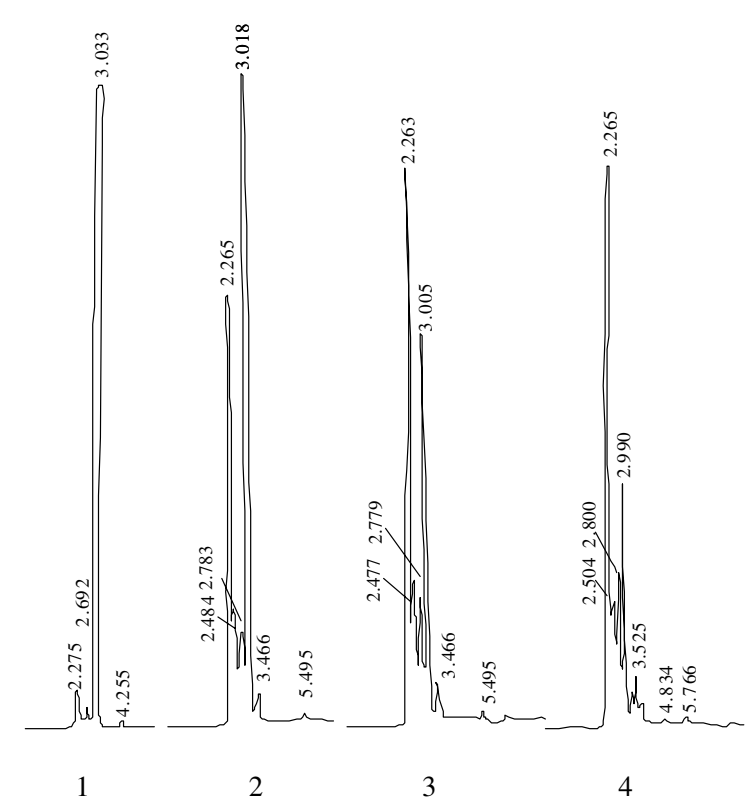

Fig. 7. High-performance liquid chromatograms (detection at $254 \mathrm{~nm}$ ) of the AR14 dye degradation solutions, recorded during the dye degradation in anode compartment, from 100 $\mathrm{mg}^{-1}$ AR14 solution with $\mathrm{pH} 7.0$, for (1) $0 \mathrm{~min}$, (2) $60 \mathrm{~min}$, (3) $120 \mathrm{~min}$, (4) $360 \mathrm{~min}$. 


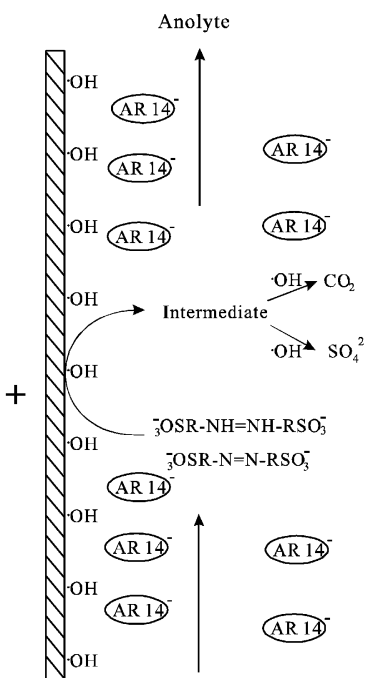

Anode

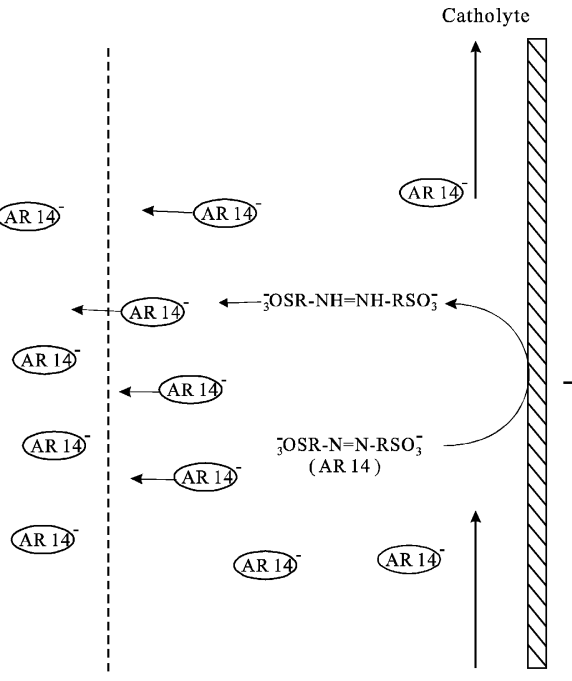

Ultrafilter Membrane
Cathode

Fig. 8. Proposed mechanism for the AR14 degradation by EK-EO process.

surface, the electroreduction on cathode surface and the electrokinetic process between anode and cathode. Fig. 8 gave a reaction scheme of the assumed EK-EO treatment of AR14.

\subsection{Improvement for AR14 degradation by regulating the current density}

The current density was changed within the technically reasonable limits of $1.5-6.25 \mathrm{~mA} \mathrm{~cm}^{-2}$. Fig. 9A and $B$ showed the effect of current density on the rate of TOC elimination as a function of time through the EKEO process. In cathode compartment, increasing the current density could result in faster removal of TOC, which indicating more AR14 was electromigrated to anode compartment as shown in the inset of Fig. 9A.

In anode compartment more organics was mineralized at higher current density. After EK-EO process for $360 \mathrm{~min}$, more than $25 \mathrm{mg} \mathrm{l}^{-1}$ TOC was removed when current density was $4.5 \mathrm{~mA} \mathrm{~cm}^{-2}$, while at $1.5 \mathrm{~mA} \mathrm{~cm}^{-2}$, only $7 \mathrm{mgl}^{-1}$ was removed. These enhancement effects were attributed to both the increasing current, which could cause a higher production of oxidizing $\mathrm{OH}$ radicals from water oxidation (Murphy et al., 1992), and the increasing concentration of organic pollutant, which might enhance the probability of collision with hydroxyl radicals (Galindo et al., 2001). But the TOC abatement at current density $6.25 \mathrm{~mA} \mathrm{~cm}^{-2}$ was not observably enhanced. This trend could be mainly associated with the parasitic reactions, such as electrolysis of water, which might compete with the electrooxidation of the contaminant (Kirk et al., 1985).
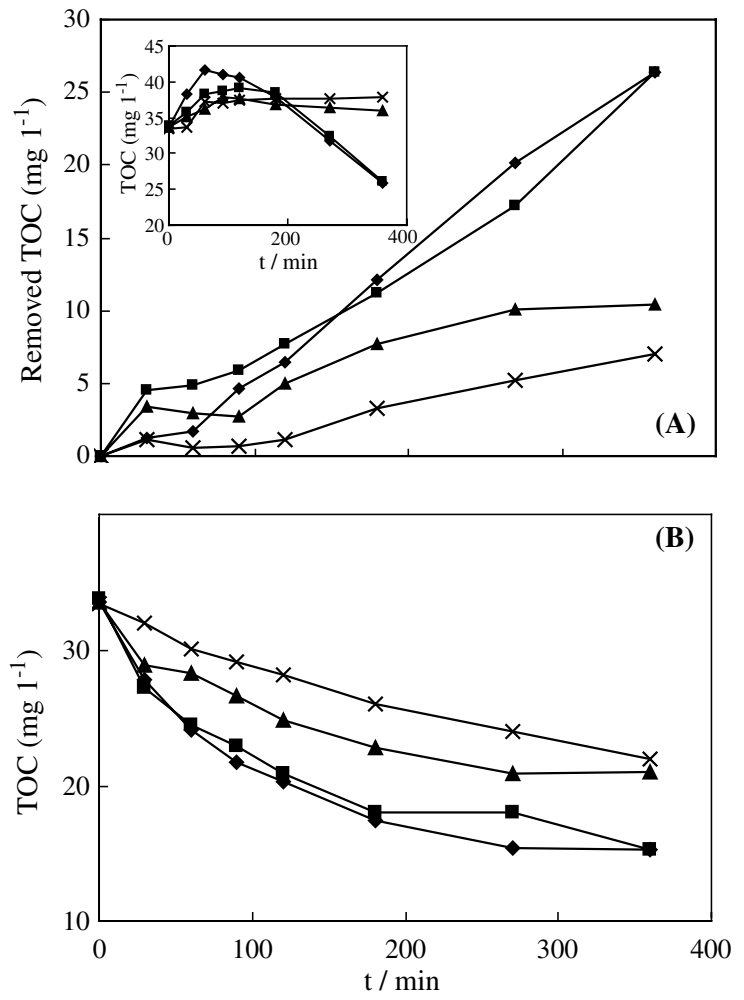

Fig. 9. Effect of current density on TOC removal in the (A) anode compartment and (B) cathode compartment for the EK-EO process. Recycling flux: $125 \mathrm{ml} \mathrm{min}^{-1}$; current density: $(--) 6.25 \mathrm{~mA} \mathrm{~cm}^{-2} ;\left(-\boldsymbol{-}_{-}\right) 4.5 \mathrm{~mA} \mathrm{~cm}^{-2} ;\left({ }_{-} \boldsymbol{\Lambda}_{-}\right) 2.5 \mathrm{~mA} \mathrm{~cm}^{-2}$ and $(-\times-) 1.5 \mathrm{~mA} \mathrm{~cm}^{-2}$. 


\subsection{Effect of the proper rate of mass transfer and reaction time on ARl4 removal}

To clarify the influence of mass transport on TOC removal, several tests in $100 \mathrm{mgl}^{-1} \mathrm{AR} 14$ aqueous solution were carried out with different recycling fluxes ranging from 10 to $185 \mathrm{ml} \mathrm{min}^{-1}$. The applied current density was $4.5 \mathrm{~mA} \mathrm{~cm}^{-2}$ and reaction time was $6 \mathrm{~h}$. As shown in Fig. 10B, the effect of mass transfer on the electromigration of AR14 was minor in the range of low flux. For example, after $6 \mathrm{~h}$ of electrolysis the TOC abatement in cathode compartment was about $50 \%$ for the recycling fluxes of 10,75 and $125 \mathrm{ml} \mathrm{min}^{-1}$. But when the recycling flux was up to $185 \mathrm{ml} \mathrm{min}^{-1}$, only approximately $40 \%$ TOC was removed. This might be due to the fact that the electromigration of AR14 could be disturbed by the recycling flux.

Both Fig. 10A and its inset suggested that in anode compartment the mineralization of AR14 was much lower at higher recycling flux than at lower flux. Though high recirculation flow velocity could enhance mass transfer and reduce diffusion layer, violent mixture might decrease the contact time of AR14 with hydroxyl radicals which were produced and adsorbed on the anode surface
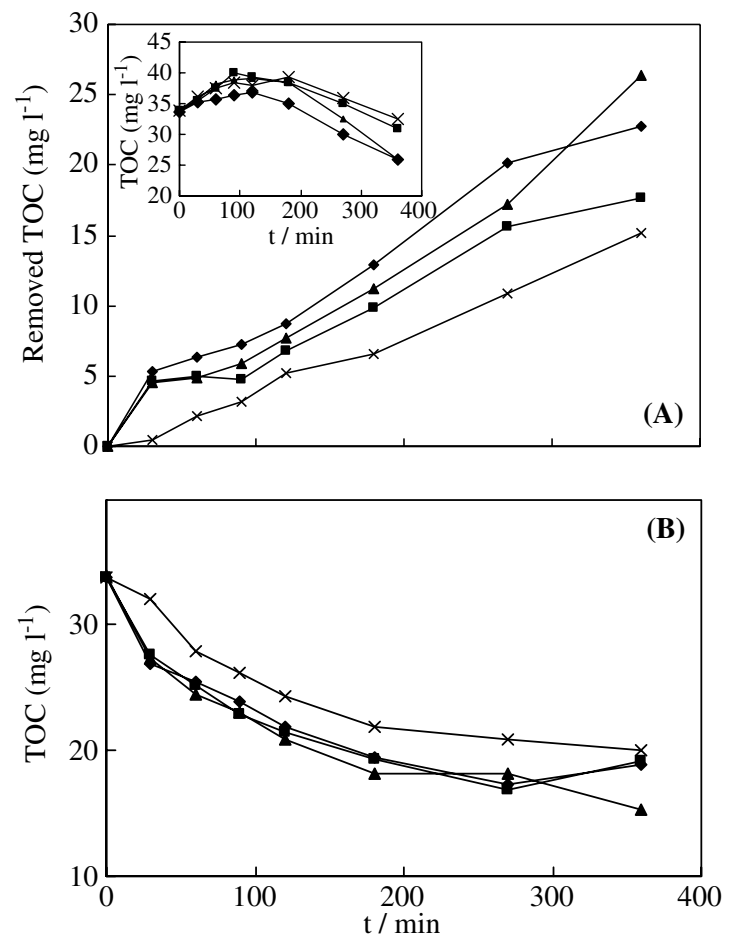

Fig. 10. Effect of recirculation liquid flow on TOC removal in the (A) anode compartment and (B) cathode compartment for the EK-EO process. Applied current density $4.5 \mathrm{mAcm}^{-2}$. Recycling flux: (--) $10 \mathrm{ml} \mathrm{min}^{-1} ;(-\boldsymbol{-}-) 75 \mathrm{ml} \mathrm{min}^{-1} ;\left(-\boldsymbol{\Delta}_{-}\right)$ $125 \mathrm{ml} \mathrm{min}^{-1}$ and $(-\times-) 185 \mathrm{ml} \mathrm{min}^{-1}$.
(Comninellis and Pulgarin, 1991). Combined with Fig. $10 \mathrm{~B}$, we found that violent mixture went against both electromigration in cathode compartment and electrooxidation in anode compartment. So the optimum recycling flux was $125 \mathrm{ml} \mathrm{min}^{-1}$ in this process.

\subsection{The influence of electrolyte concentration on AR14 removal}

Different contents of $\mathrm{Na}_{2} \mathrm{SO}_{4}$ in aqueous solution were employed to investigate the effect of electrolyte concentration on AR14 removal in EK-EO process. Fig. 11 described the experimental results for the EKEO process with four electrolyte concentrations.

In cathode compartment the electromigration of AR14 was significantly affected by the initial electrolyte concentration. As shown in Fig. 11B, when the initial $\mathrm{Na}_{2} \mathrm{SO}_{4}$ concentration was $0.08 \mathrm{M}$, after electrolysis for $360 \mathrm{~min}$, only approximately 10\% AR 14 was transferred into anode compartment, while almost $60 \%$ transferred at $0.01 \mathrm{M} \mathrm{Na}_{2} \mathrm{SO}_{4}$. This could be explained by Eq. (3), which formalized the dependence of the transference number of an individual ion on its ionic mobility, concentration, and the total electrolyte concentration (or
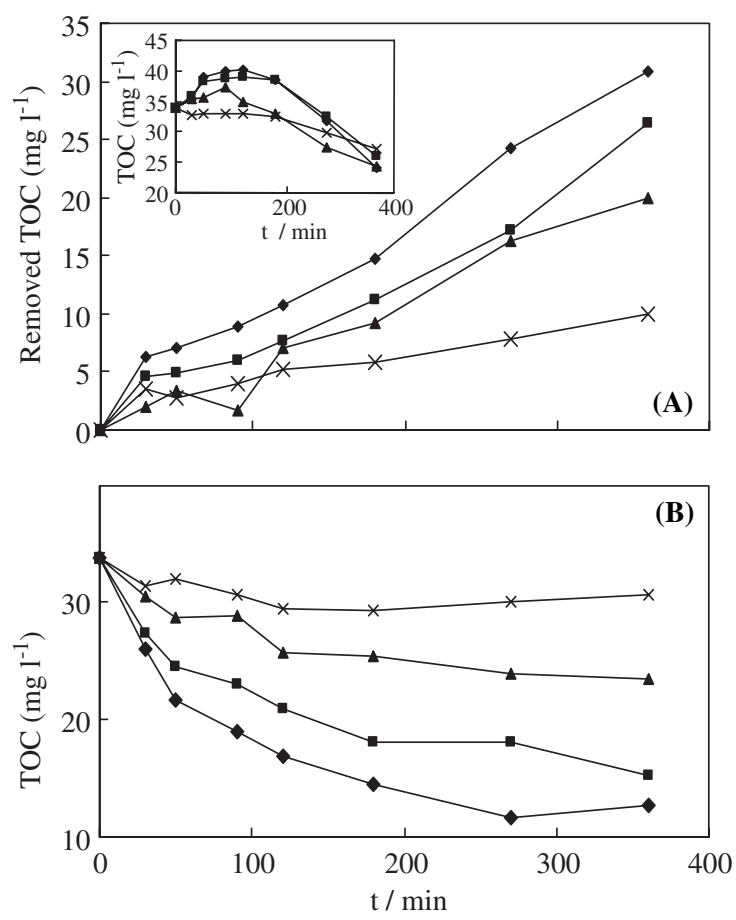

Fig. 11. Effect of electrolyte concentration on TOC removal in the (A) anode compartment and (B) cathode compartment for the EK-EO process. Current density: $4.5 \mathrm{~mA} \mathrm{~cm}^{-2}$; recirculation liquid flow: $125 \mathrm{ml} \mathrm{min}^{-1} ; \mathrm{Na}_{2} \mathrm{SO}_{4}$ concentration: $(--)$

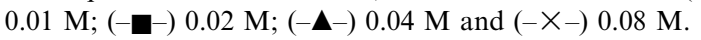


the electrolyte ionic strength) in the aqueous solution. The total current $I$ could be related to the migrational mass flux of each species through Faraday's law for equivalence of mass flux and charge flux.

$I=\sum_{j} t_{j} I=\frac{Z_{j} u_{j}^{*} c_{j}}{\sum_{1}^{n} Z_{i} u_{i} c_{i}} I$

where $Z_{j}, u_{j}, c_{j}$ and $t_{j}$ were the valence, the effective ionic mobility, the molar concentration and the transport (or transference) number of ion $j$, respectively. Eq. (3) implied that as the concentration of a species decreased relative to the total electrolyte concentration in the fluid, its transport and removal under a given electrical currents would be less efficient. Therefore, it was reasonable to assume that the efficiency of removal of a specific species decreased in time as its concentration with respect to other species in the fluid decreases. The results of TOC change given in the inset of Fig. 11A also suggested less organic material was electromigrated into anode compartment at high electrolyte concentrations.

Moreover, at a certain current, increasing electrolyte concentration might result in decreasing of the applied potential. As demonstrated in Fig. 11A, in anode compartment the higher electrolyte concentration was, the less organic pollutant was oxidized. The lower TOC decay could be explained by both the lower potential and the less electromigration as previously discussed.

\section{Conclusions}

This paper presented a new EK-EO process for mineralization and decoloration of anionic organic substances in aqueous solution. This EK-EO process combined the electrokinetic effect of anionic purities under an electric field with the electrooxidation effect of anode reaction. Based on the experimental results presented above, the following conclusions were drawn:

1. The EK-EO process was effective for degradation and decoloration of an anionic azo dye AR14 in the simulated wastewater.

2. The test results suggested that both electrooxidationelectroreduction and electromigration pathways coexisted in EK-EO process. The electrooxidation resulted in mineralization of organic pollutant. The electromigration of AR14 might lead to comparatively high specific abatement efficiencies. The electroreduction partly contributed to decoloration of AR14 in cathode compartment.

3. Several aspects, such as current density, recycling flux and electrolyte concentration, were explored to determine their effect on the treatment efficiency of EKEO process. High current density, low recycling flux and low electrolyte concentration significantly enhanced the treatment efficiency. At the optimum condition: the current density of $4.5 \mathrm{~mA} \mathrm{~cm}^{-2}$, recycling flux of $125 \mathrm{ml} \mathrm{min}^{-1}$ and electrolyte concentration of $0.02 \mathrm{M}$, after $360 \mathrm{~min}$ electrolysis of 100 $\mathrm{mgl}^{-1}$ AR14 solutions, complete discoloration of AR14 was observed in both the cathode and anode compartment, about $60 \%$ TOC was electromigrated in cathode compartment, and more than $25 \mathrm{mgl}^{-1}$ TOC was abated in anode compartment.

\section{Acknowledgements}

The authors appreciate the generous financial support of this work by National Science Fund for Distinguished Young Scholars (no. 50225824) and National Natural Science Foundation of China (20337020).

\section{References}

Acar, Y.B., Li, H., Gale, R.J., 1992. Phenol removal from kaolin by electrokinetics. J. Geotech. Eng. 118, 1837-1852.

Acar, Y.B., Alshawabkeh, A.N., 1993. Principles of electrokinetic remediation. Environ. Sci. Technol. 27, 2638-2647.

Acar, Y.B., Gale, R.J., Alshawabkeh, A.N., Marks, R.E., Puppula, S., Bricka, M., Parker, R., 1995. Electrokinetic remediation: basics and technology status. J. Hazard. Mater. 40, 117-137.

Andreozzi, R., Caprio, V., Insola, A., Marotta, R., 1999. Advanced oxidation processes (AOP) for water purification and recovery. Catal. Today 53, 51-59.

Bechtold, T., Mader, C., Mader, J., 2002. Cathodic decolourization of textile dyebaths: tests with full plant. J. Appl. Electrochem. 32, 943-950.

Coin, R.J., Niksa, M.J., Elyanow, D.I., 1996. Wastewater treatment enhanced by electrochemistry. Environ. Prog. 15, 122-127.

Comninellis, Ch., Pulgarin, C., 1991. Anodic oxidation of phenol for waste water treatment. J. Appl. Electrochem. 21, 703-708.

Comninellis, Ch., Pulgarin, C., 1993. Electrochemical oxidation of phenol for wastewater treatment using $\mathrm{SnO}_{2}$ anodes. J. Appl. Electrochem. 23, 108-112.

Dzenitis, J.M., 1997. Steady state and limiting current in electroremediation of soil. J. Electrochem. Soc. 144, 13171322.

Galindo, C., Jacques, P., Kalt, A., 2001. Photochemical and photocatalytic degradation of an indigoid dye: a case study of acid blue 74 (AB74). J. Photochem. Photobiol. A: Chem. $141,47-56$.

Jüttner, K., Galla, U., Schmieder, H., 2000. Electrochemical approaches to environmental problems in the process industry. Electrochim. Acta 45, 2575-2594.

Kirk, D.W., Shrifian, H., Foulkes, F.R., 1985. Anodic oxidation of aniline for waste water treatment. J. Appl. Electrochem. 15, 285-292.

Murphy, O.J., Hitchens, G.D., Kaba, L., Verotsko, C., 1992. Direct electrochemical oxidation of organics for wastewater treatment. Water Res. 26, 443-451. 
Panizza, M., Bocca, C., Cerisola, G., 2000. Electrochemical treatment of wastewater containing polyaromatic organic pollutants. Water Res. 34, 2601-2605.

Pulgarin, C., Alder, N., Peringer, N., Comninellis, Ch., 1994. Electrochemical detoxification of a 1,4-benzoquinone solution in wastewater treatment. Water Res. 28, 887-893.

Rajeshwar, K., Ibaňez, J.G., Swain, G.M., 1994. Electrochemistry and environment. J. Appl. Electrochem. 24, 1077-1091.

Rodger, J.D., Bunce, N.J., 2001. Electrochemical treatment of 2,4,6-trinitrotoluene and related compounds. Environ. Sci. Technol. 35, 406-410.

Saichek, R.E., Reddy, K.R., 2003. Effect of $\mathrm{pH}$ at the anode for the electrokinetic removal of phenanthrene from kaolin soil. Chemosphere 51, 273-287.

Schümann, U., Gründler, P., 1998. Electrochemical degradation of organic substances at $\mathrm{PbO}_{2}$ anodes: monitoring by continuous $\mathrm{CO}_{2}$ measurements. Water Res. 32, 2835-2842.

Simmon, D., 1997. Electrochemistry for a cleaner environment. Chem. Soc. Rev. 26, 181-189.
Solozhenko, E.G., Soboleva, N.M., Goncharuk, V.V., 1995. Decolourization of azodye solutions by Fenton's oxidation. Water Res. 29, 2206-2210.

Trasatti, S., 1995. Electrochemistry and environment: the role of electrocatalysis. Int. J. Hydrogen Energy 20, 835-844.

Vandevivere, P.C., Bianchi, R., Verstraete, W., 1998. Treatment and reuse of wastewater from the textile wet-processing industry: review of emerging technologies. J. Chem. Technol. Biotechnol. 72, 289-302.

Wang, Q., Lemley, A.T., 2002. Oxidation of diazinon by anodic Fenton treatment. Water Res. 36, 3237-3244.

Wu, F., Deng, N.S., Hua, H.L., 2000. Degradation mechanism of azo dye C. I. Reactive red 2 by iron powder reduction and photooxidation in aqueous solutions. Chemosphere 41, $1223-1238$.

Xiong, Y., Strunk, P.J., Xia, H.Y., Zhu, X.H., Karlsson, H.T., 2001. Treatment of dye wastewater containing acid orange II using a cell with three-phase three-dimensional electrode. Water Res. 35, 4226-4230. 